\title{
Reactive powder concrete plate response to a flat projectile impact
}

\author{
Y.-S. Tai \& C.-C. Tang \\ Department of Civil Engineering, ROC Military Academy, \\ Taiwan, Republic of China
}

\begin{abstract}
Reactive powder concrete (RPC), which is a composite that has been developed in recent years, is a special mixture that is cured especially to have a higher compressive strength than that of concrete (about $200 \mathrm{MPa}$ ). Adding a few steel fibers can greatly improve its tensile and bending strength, its impact resistance, and its toughness. It is therefore expected to be used to containment structures of nuclear power plants and protect military facilities. In this study, high-velocity impact experiments were conducted to assess the resistance of the ultra-high strength concrete targets. Test variables include impact velocity and the addition of steel fibers. The results of the test show that RPC plates, because of their higher compressive strength, are more fragile than $\mathrm{NC}$ plates but on addition of a small amount of steel fibers a significant improvement in impact resistance was observed in the target plates. In addition, a numerical simulation using the nonlinear finite element code LS-DYNA was also performed. The Johnson-Holmquist concrete material constitutive model was used. The numerical results are in agreement with the results obtained from the experiment. Keywords: impact experiment, RPC, steel fiber reinforced concrete, numerical simulations.
\end{abstract}

\section{Introduction}

The response of concrete to transient dynamic loading is investigated extensively for both civil and military applications. In the past, for a structure to have greater impact resistance, mostly a higher reinforcement ratio was adopted or the thickness of structural members was increased. Because the reinforcement is too dense in structural members, the concrete is quite difficult to cast. In modern 
civil engineering, the high-strength concrete (HSC) and high-performance concrete (HPC) are becoming more extensively used. This is because most of the rheological, mechanical, and durability properties of these materials are better than those of conventional concretes. Hanchak et al. [1] employed an ogivenosed projectile with different ballistic velocities on reinforced concrete targets with compressive strengths of 48 and $140 \mathrm{MPa}$ to study the changes in residual velocity after perforation. Dancygier and Yankelevsky [2] conducted tests on high-strength concrete (HSC) subjected to impact loads. It was observed that the projectile penetration depth in HSC was less than that in regular strength concrete (RSC). O'Neil et al. [3] found that the penetration depth induced by $0.9 \mathrm{~kg}$ projectiles in vary high-strength concrete with a compressive strength of $180 \mathrm{MPa}$ was approximately $50 \%$ less than that in concrete with a compressive strength of $35 \mathrm{MPa}$, and about $30 \%$ less than that in concrete with a strength of $104 \mathrm{MPa}$. Luo et al. [4] studied high performance steel fiber reinforced concrete with a compressive strength of $116 \mathrm{MPa}$ subjected to high velocity impact of projectile and compared with those targets made of reinforced high strength concrete (RHSC) with a compressive strength of $72 \mathrm{MPa}$. Zhang et al. [5] presented the results of experimental study on concrete with compressive strengths of 45 to $235 \mathrm{MPa}$. The results indicated that the penetration depth and crater diameter in target specimens decreased progressively with improved compressive strength of the concrete.

Reactive powder concrete (RPC), otherwise known as ultra-high-performance concrete, was developed through micro-structural enhancement techniques for cementitious materials. As compared to normal cement-base materials, the primary improvements of RPC include the compressive strength of the range between 200 and $800 \mathrm{MPa}$, fracture energy of the range between 1200 and $40000 \mathrm{~J} / \mathrm{m}^{2}$ (Richard and Cheyrezy [6], Chan and Chu [7]). Incorporating steel fibers can substantially improve its tensile and bending strength, its impact resistance, and its toughness. This is generally achieved by micro-structural engineering approach, including elimination of the coarse aggregates, reduction of the water-to-cementitious material, lowing of the $\mathrm{CaO}-\mathrm{SiO}_{2}$ ratio by introducing the silica components. It is therefore expected that it will be used in protecting military facilities and nuclear power plants. The main objective of this research is to study the dynamic response and failure mode of normal concrete (NC) and RPC target plates subjected to high-velocity impacts. Some results are obtained by numerical simulation. Finally, a comparison of the numerical and experimental results is presented.

Table 1: $\quad$ Mix proportions $\left(\mathrm{kg} / \mathrm{m}^{3}\right)$.

\begin{tabular}{|c|c|c|c|c|c|c|c|c|c|}
\hline Mix no. & w/c & cement & $\begin{array}{c}\text { Silica } \\
\text { fume }\end{array}$ & water & $\begin{array}{c}\text { Coarse } \\
\text { aggregate }\end{array}$ & $\begin{array}{c}\text { fine } \\
\text { aggregate }\end{array}$ & $\begin{array}{c}\text { quartz } \\
\text { sand }\end{array}$ & $\begin{array}{c}\text { Crushed } \\
\text { quartz }\end{array}$ & $\begin{array}{c}\text { Steel } \\
\text { fiber }\end{array}$ \\
\hline NC & 0.44 & 401 & --- & 178 & 1119 & 672 & --- & --- & --- \\
\hline NC-F2 & 0.44 & 401 & --- & 178 & 1119 & 672 & --- & --- & $2 \%$ \\
\hline RPC & 0.28 & 720 & 216 & 204 & --- & --- & 900 & 252 & --- \\
\hline RPC-F1 & 0.28 & 720 & 216 & 204 & --- & --- & 900 & 252 & $1 \%$ \\
\hline RPC-F2 & 0.28 & 720 & 216 & 204 & --- & --- & 900 & 252 & $2 \%$ \\
\hline RPC-F5 & 0.28 & 720 & 216 & 204 & --- & --- & 900 & 252 & $5 \%$ \\
\hline
\end{tabular}




\section{Experimental program}

\subsection{Materials}

The mixture proportions for RPC, normal strength concrete investigated in this study are given in Table 1. For RPC, ASTM Type II portland cement; fine quartz sand (approximately 150 600 $\mu \mathrm{m}$ ); crushed quartz powder (approximately $5 \sim 25 \mu \mathrm{m}$ ).; dry non-compacted silica fume (approximately $0.1 \sim 0.2 \mu \mathrm{m}$ ); Acrylic graft-copolymer retarding admixture; and steel fibers $(12 \mathrm{~mm}$ in length and $0.175 \mathrm{~mm}$ in diameter) were used.

\subsection{Mix proportions and casting of specimens}

Mix proportioning per cubic meter of concrete are shown in Table 1. The concrete mixes were prepared using a Hobart type laboratory mixer of $0.15 \mathrm{~m}^{3}$ capacity. The cement, quartz fume, silica fume, and silica sand were mixed first, followed by the addition of water containing the required amount of superplasticizer. The final mixing stage involved the addition of steel fibers. Fibers were added to concrete at 80,160 , and $400 \mathrm{~kg}$ per cubic meter of concrete; this is equivalent to $1.0 \%, 2.0 \%$, and $5.0 \%$ by volume of concrete. After casting, the specimens were covered with a plastic membrane to prevent the moisture from evaporating and were stored in the laboratory at $25^{\circ} \mathrm{C}$ for 24 hours and then de-molded and placed in a thermostat water tank at $90^{\circ} \mathrm{C}$ for curing for 96 hours.

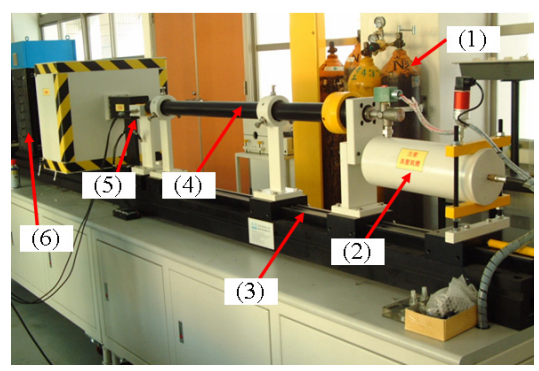

Figure 1: Gas gun (1)nitrogen bottle; (2)high pressure tank; (3)support; (4) barrel; (5) velocity measurement; (6)target frame.

\subsection{Experimental set-up}

The experimental set-up, are shown in Fig. 1. It consists of the nitrogen bottle; the high pressure tank; the support and barrel; the velocity measuring system; target fixed frame; and the central control unit. The projectile is launched and it impacts the target plate when the pressure valve is triggered. Two pairs of interceptive grating sensors with LED light sources on the trajectory of the projectile are used to measure the velocity of impact just before it strikes the target plate. In this investigation, flat-ended projectiles with a diameter of $25 \mathrm{~mm}$, length of $75 \mathrm{~mm}$, and mass of $297 \mathrm{~g}$ were fabricated from SKH-51 tool steel. The target was clamped in a square frame as shown in Fig. 2. 


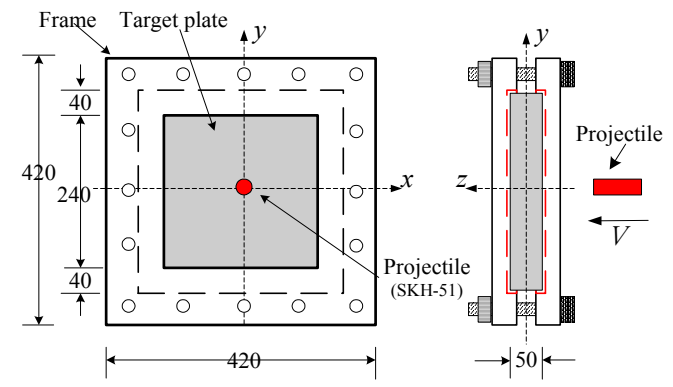

Figure 2: Scheme of the arrangement used for clamping the target plate to the steel frame (unit: $\mathrm{mm}$ ).

\section{Experimental results and discussions}

The impact resistance performance of the NC and RPC plates containing various volume fractions of steel fibers are discussed. Photographs were taken after impact; the penetration depth, crater areas, and final state of the projectile were measured as the damage criteria. The penetration depth is measured as the actual distance traveled by the projectile. For measurement of irregular crater areas an image analysis system and a reference measuring rule are used, according to the dot per inch (dpi) values of the photographs to calculate the area of the closed region. The results of all tests are summarized in Table 2. Fig. 3(a)-(f) shows the damage on the rear faces of the target plates. Post experiment examinations showed that the failure of an NC plate under a low velocity impact $(27-56.8 \mathrm{~m} / \mathrm{sec}$ ) was destructive (Fig. 3(a)). The target plates were divided into several pieces. The cause of failure conjectured that during the contact period when the projectile impacts the plates, very high stresses developed in the vicinity of the impact area which led to the formation of a shear-cone shaped fracture zone. The plate loses integrity and obtains momentum, experiencing large displacements leading to serious damage. For the plates containing $2 \%$ by volume of steel fibers (NC-F2) such as NC-F2-1, under an impact velocity from about 41.7 to $64.1 \mathrm{~m} / \mathrm{sec}$, there is no perforation and the damage is slight. Target plates NC-F2-2 and NC-F2-3 maintained their integrity after being perforated under a relatively higher velocity impact (Fig. 3(b)). The addition of steel fibers can significantly restrain crack propagation through the bridging effect. However, because the compression strength and split strength of the concrete are relatively low; the target is poor in impact resistance performance. For ultra-high strength concrete RPC, the compression strength is greater than 6.4 times that of normal concrete. Its mechanical behavior is purely linear and elastic when steel fibers are not added. The corresponding fracture energy, defined as the area beneath the load-deflection curve, does not exceed $30 \mathrm{~J}$ [6]. Thus, cracks are more apt to form and propagate in such targets due to the brittleness of the material and the targets collapsed as though smashed when subjected to different impact velocities (Fig. 3(c)). For RPC, addition of steel fibers leads to a small increase in compression strength, but with the bridging effect in which they cross 
the path of potential cracks, along with the good bond between fiber and concrete, there is better resistance to fiber pullout during cracks and these can significantly restrain crack propagation. This greatly increases the toughness and fracture energy of the RPC. Because toughness and fracture energy are important criteria in the impact resistance performance, it depends upon the volume of fiber added to the concrete. This means that the target plate damage will be reduced with the addition of higher volumes of steel fibers. From the test data in Table 2 and Fig. 3(d)-(f), it appears that the size of the crater zone decreases and becomes more localized as the volume of steel fibers included was increased from $1 \%$ to $2 \%$ and $5 \%$. Fig. 4 compares the test results for crater area. The severity of damage of RPC without the addition of steel fibers under a lowvelocity impact is clearly seen. The crater area was reduced about $50 \%$ on addition of $1 \%$ steel fibers, and the failure mode changed from brittle to pseudo plastic. In addition, the crater area is obvious reduced with the addition of $5 \%$ steel fibers.

Table 2: $\quad$ Summary of impact test results.

\begin{tabular}{|c|c|c|c|c|c|c|c|}
\hline \multirow{2}{*}{ Test no. } & \multirow{2}{*}{$\begin{array}{l}\text { Compressive } \\
\text { strength } \\
\text { (MPa) }\end{array}$} & \multirow{2}{*}{$\begin{array}{c}\text { Split } \\
\text { strength } \\
(\mathrm{MPa})\end{array}$} & \multirow{2}{*}{$\begin{array}{l}\text { Impact } \\
\text { velocity } \\
(\mathrm{m} / \mathrm{sec})\end{array}$} & \multirow{2}{*}{$\begin{array}{l}\text { Initial } \\
\text { kinetic } \\
\text { energy } \\
\text { (J) }\end{array}$} & \multicolumn{3}{|c|}{ Damage } \\
\hline & & & & & $\begin{array}{c}\text { Penetration } \\
\text { depth } \\
(\mathrm{mm})\end{array}$ & \begin{tabular}{|c|} 
Scabbing \\
area \\
$\left(\mathrm{mm}^{2}\right)$
\end{tabular} & $\begin{array}{c}\text { Final state of } \\
\text { projectile }\end{array}$ \\
\hline NC-1 & \multirow{3}{*}{25.0} & \multirow{3}{*}{2.6} & 27.0 & 107.5 & 0.6 & 10354 & $\mathrm{PR}^{\mathrm{SD}}$ \\
\hline $\mathrm{NC}-2$ & & & 35.7 & 188.0 & NA & 11223 & $\mathrm{PF}^{\mathrm{HD}}$ \\
\hline NC-3 & & & 56.8 & 479.1 & NA & 16300 & $\mathrm{PF}^{\mathrm{HD}}$ \\
\hline NC-F2-1 & \multirow{3}{*}{25.2} & \multirow{3}{*}{3.1} & 41.7 & 258.2 & 5.3 & SD & PR \\
\hline NC-F2-2 & & & 56.8 & 479.1 & NA & 10385 & PF \\
\hline NC-F2-3 & & & 64.1 & 610.2 & NA & 9010 & $\mathrm{PF}$ \\
\hline RPC-1 & \multirow{3}{*}{161.9} & \multirow{3}{*}{7.3} & 34.7 & 177.6 & NA & 23520 & $\mathrm{PC}^{\mathrm{SD}}$ \\
\hline RPC-2 & & & 58.5 & 504.8 & NA & 28865 & $\mathrm{PF}^{\mathrm{HD}}$ \\
\hline RPC-3 & & & 76.0 & 852.0 & NA & NA & $\mathrm{PF}^{\mathrm{HD}}$ \\
\hline RPC-F1-1 & \multirow{3}{*}{175.3} & \multirow{3}{*}{13.8} & 58.2 & 499.6 & 1.8 & 14521 & PR \\
\hline RPC-F1-2 & & & 76.0 & 852.0 & NA & 14202 & $\mathrm{PC}$ \\
\hline RPC-F1-3 & & & 104.0 & 1595.4 & NA & 14409 & $\mathrm{PC}$ \\
\hline RPC-F2-1 & \multirow{3}{*}{178.3} & \multirow{3}{*}{21.9} & 76.0 & 852.0 & 3.4 & 11619 & PR \\
\hline RPC-F2-2 & & & 85.0 & 1065.7 & 4.7 & 14297 & PR \\
\hline RPC-F2-3 & & & 104.0 & 1595.4 & 5.5 & 18741 & PR \\
\hline RPC-F5-1 & \multirow{3}{*}{192.8} & \multirow{3}{*}{31.6} & 58.5 & 504.8 & 1.4 & ND & PR \\
\hline RPC-F5-2 & & & 78.1 & 899.7 & 2.9 & 816 & PR \\
\hline RPC-F5-3 & & & 104.1 & 1598.4 & 4.7 & 8554 & PR \\
\hline
\end{tabular}

\section{Numerical simulations}

This study simulates the experiment (Specimen no: RPC-F1-3) in Section 3 using LS-DYNA, (LSTC [8]) which is a general purpose finite element code for analysis of large deformations, penetration, and failure response dynamics of structures based on explicit time integration. Concrete models are generally based on the phenomenological behavior at the macroscopic level when a 
concrete is subjected to impact loading. The constitutive law has to employ the plastic flow rule on its principal stress space to differentiate between the hydrostatic and deviatory stress portions. Different loading functions are used respectively to describe the behavior of the two parts. In the lower pressure zone, it is described in terms of the deviatory stress. In the impacting process where the shock pressure induced in the material interior is as high as its maximum strength, the deviatory stress portion has a small influence. The Hugoniot shock pressure and specific volume relationship - the equation of state (EOS) is used to replace the stress-strain relationship. In addition, the influence of strain rates and material damages is considered in material models. To fully describe the concrete's dynamic effect within the impact procedure, several concrete models have been implemented in LS-DYNA, designed for special purposes such as damage and effect of strain rate and cracks (Malvar et al. [9]; Ågårdh and Laine [10]). This investigation uses the "Johnson-Holmquist Concrete" model, based on the work of Holmquist et al. (Holmquist et al. [11]; Johnson [12]) to forecast material dynamic behavior. The calculations for these material parameters in the constitutive law have been published by [11]. In this study, all the parameters were calculated from the experimental data, and the EOS is according to the experimental results by Hanchak et al. [1] and is used after the calibration of the parameters. The material parameters are presented in Table 3.
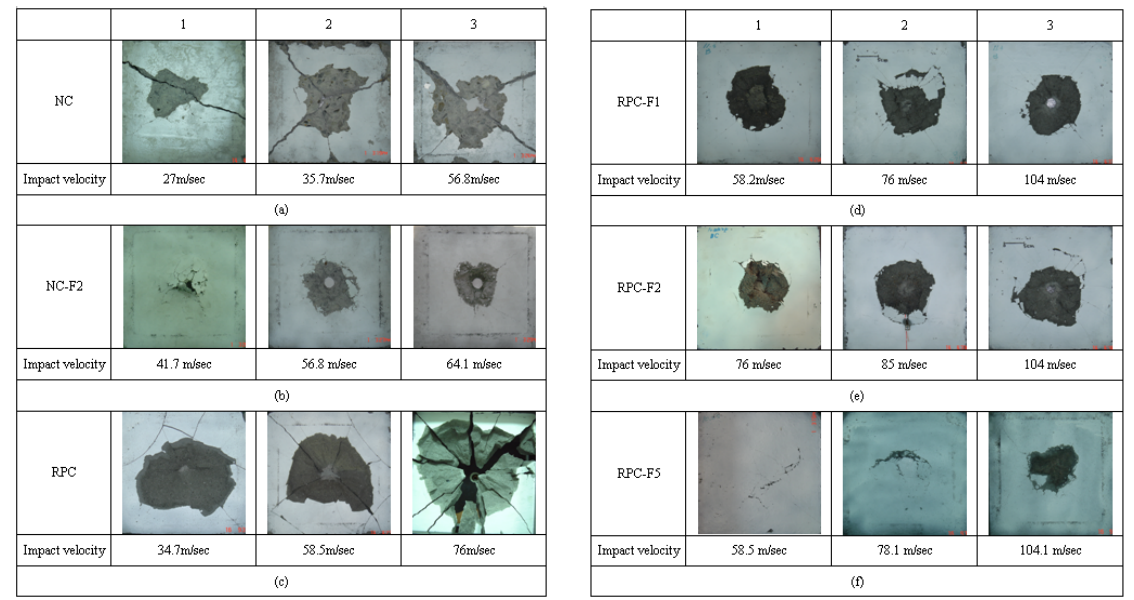

Figure 3: $\quad$ Rear face damage patterns of the plates.

\subsection{Mesh description and boundary conditions}

The analytical configuration considered in this study is shown in Fig. 3. A concrete target plate is clamped between two steel frames and the steel projectile impacts the center of the plate normally. With the assumption that the clamp and impact are fully symmetric, only a quarter of the test arrangement was modeled to reduce the size of the computational domain. The boundary conditions for the numerical model are shown in Fig. 5. Symmetric boundary conditions are imposed on the center line of the plate and clamp boundary conditions are 
imposed on the outer edge. The concrete specimen is modeled using 69914 six-node wedge elements and the projectile is modeled using 780 eightnode hexagonal elements. These elements are single-point integration elements with hour-glass control. In addition, the initial velocity adopted for the projectile is $104 \mathrm{~m} / \mathrm{sec}$ that is measurement by experiment. Fig. 6 shows the finite element model of the concrete target and the steel projectile.

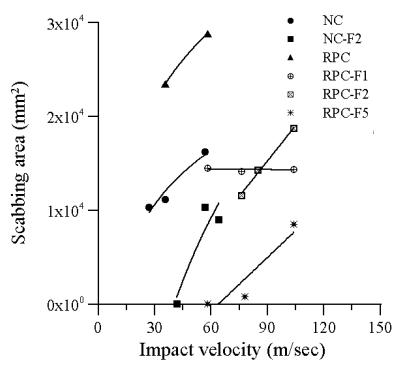

Figure 4: $\quad$ Comparison of the crater area.

Table 3: $\quad$ The material parameters for the concrete model.

\begin{tabular}{|c|c|c|c|c|c|c|c|}
\hline \multirow{2}{*}{ Density, } & \multirow{2}{*}{$\begin{array}{l}\text { Shear } \\
\text { modulus, } \\
\mathrm{MPa}\end{array}$} & \multicolumn{6}{|c|}{ Strength constants } \\
\hline & & A & B & $\mathrm{N}$ & $\mathrm{C}$ & $f_{c}^{\prime}$ & $S_{\max }$ \\
\hline 2600 & $25.9 \times 10^{3}$ & 0.75 & 1.6 & 0.61 & 0.007 & 175.3 & 3.5 \\
\hline \multicolumn{2}{|c|}{$D_{1}$} & \multicolumn{3}{|c|}{$D_{2}$} & \multicolumn{3}{|c|}{$\left(\varepsilon_{p}^{f}+\mu_{p}^{f}\right)_{\min }$} \\
\hline \multicolumn{2}{|c|}{0.33} & & 1.0 & & \multicolumn{3}{|c|}{0.08} \\
\hline $\begin{array}{l}P_{\text {crush }} \\
\mathrm{MPa}\end{array}$ & $\mu_{\text {crush }}$ & $\begin{array}{c}K_{1} \\
\mathrm{GPa}\end{array}$ & $\begin{array}{c}K_{2} \\
\mathrm{GPa}\end{array}$ & $\begin{array}{c}K_{3} \\
\mathrm{GPa}\end{array}$ & & $\begin{array}{l}\text { lock } \\
\mathrm{GPa}\end{array}$ & $\mu_{\text {lock }}$ \\
\hline 58.4 & 0.0017 & 85.0 & -171.0 & 208 & & 0.8 & 0.1 \\
\hline
\end{tabular}

\subsection{Numerical results and discussion}

The analysis was conducted for a projectile impact velocity of $104 \mathrm{~m} / \mathrm{sec}$ on a PC with P4 $1.8 \mathrm{GHz}$ processor and was used for about 5 hours. Post processing was performed using LS-Prepost v.1.0. The results of the analysis are shown in Fig. 8-11. Solutions are terminated after $500 \mu$ s. Fig. 7 illustrates the time history of the velocity when the projectile impacts the target plate. Fig. 8 gives the time history of the contact force at the interface between the projectile and the target. During the initial contact between the projectile and the target, the force is increased immediately. Owing to the inertia, the force causes a high-frequency oscillation response in about $\mathrm{t}=50-60 \mu \mathrm{s}$. Then, the contact force is reduced with the speed of striking, dropping to zero in about $t=125 \mu \mathrm{s}$. Fig. 9 illustrates the penetration process of the projectile and the failure pattern of the target. At the moment of contact, flared shear cracks are immediately formed in a region in the periphery of the projectile. In addition, the compressive wave reflected from the rear face of the target changes to a tensile wave that interacts with the 
compressive wave and leads to a rear crater (Fig. 9(b)). The clamp boundary conditions imposed on the outer edge result in tensile stresses at the boundary of the target and the vertical cracks are visible (Fig. 9(c)). The velocity of the projectile falls quickly when it makes contact with the target and falls to zero in about $\mathrm{t}=0.125 \mathrm{~ms}$; however, the cracks and the crater extend continuously because of the inertia. The final damage pattern is similar to the results of the experiment (Fig. 10).

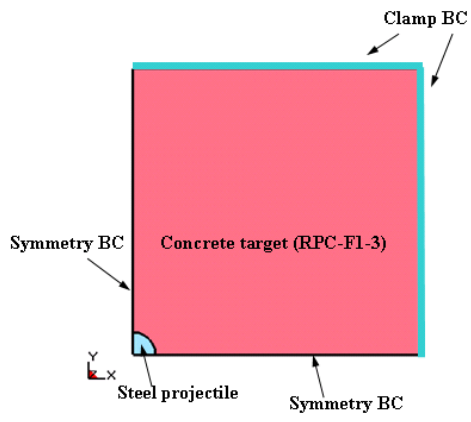

Figure 5: Boundary conditions for analysis.

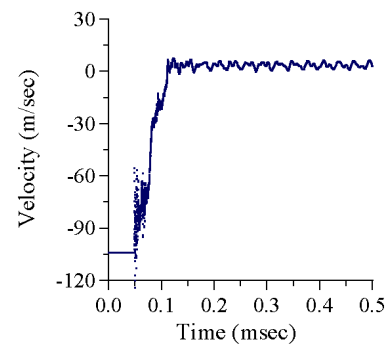

Figure 7: The time history of the projectile velocity during penetration.

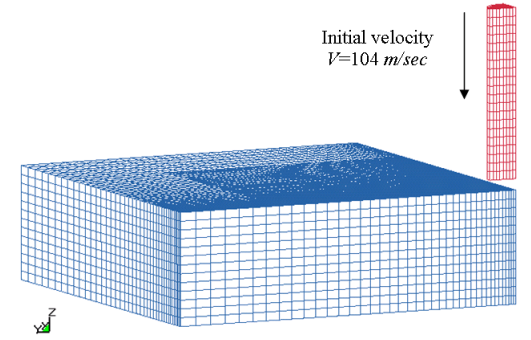

Figure 6: Finite element model of the target and the projectile.

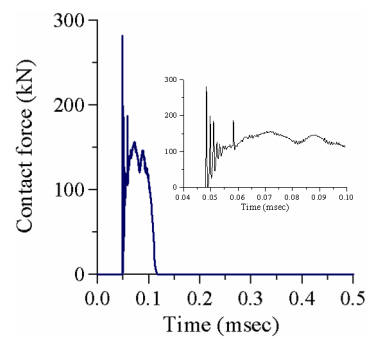

Figure 8: The time history of the contact force in at the projectile-target interface.

\section{Conclusions}

In this work, the impact resistance performance of RPC and NC with various volume fractions of steel fibers under different impact velocities is investigated. The tests lead to the following conclusions: (1) RPC is a special mixture that has been cured especially to have an ultra-high compressive strength. However, it is highly fragile when mixed without any steel fibers. Thus, when the failure conditions occur, the plates collapses though smashed. (2) Steel fibers can increase the split tensile strength and can decrease brittleness. With $2 \%$ and $5 \%$ by volume of steel fibers as examples, split tensile strength values of 21.9 and 31.6 MPa were attained, approximately equal to the compressive strength of NC. 
This enhances impact resistance performance. (3) The Johnson-Holmquist concrete material constitutive model has been implemented in the finite element code LS-DYNA. The preliminary computations demonstrate reasonable correlation with experimental data, which allow us to conclude that using the model, the concrete dynamic effect and its cracking failure behavior at high pressures and high strain rates can be fully described. In addition, the numerical simulations yield details of the penetration processes, and the variation of the contact force at a velocity of $104 \mathrm{~m} / \mathrm{sec}$.

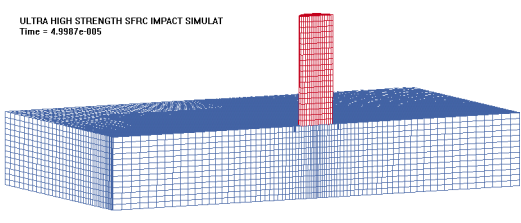

(a) $\mathrm{t}=0.05 \mathrm{~ms}$

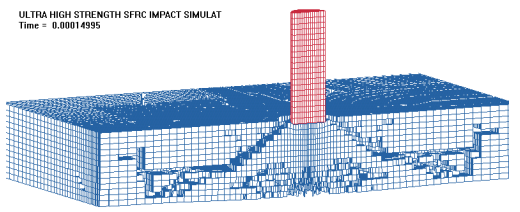

(c) $\mathrm{t}=0.15 \mathrm{~ms}$

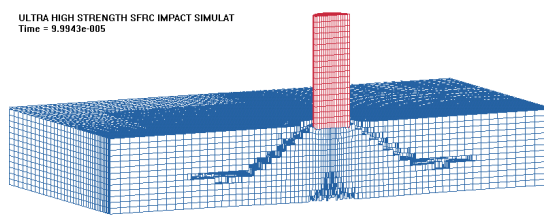

(b) $\mathrm{t}=0.1 \mathrm{~ms}$

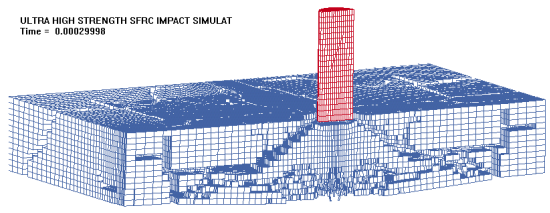

(d) $\mathrm{t}=0.3 \mathrm{~ms}$

Figure 9: Impact processes and failure model.

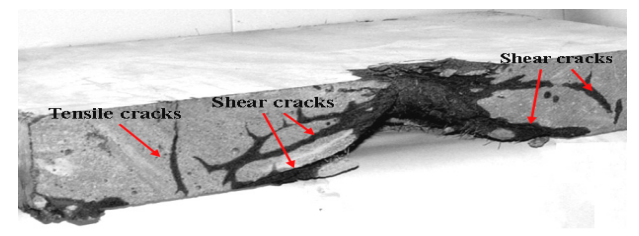

(a) Experimental test result

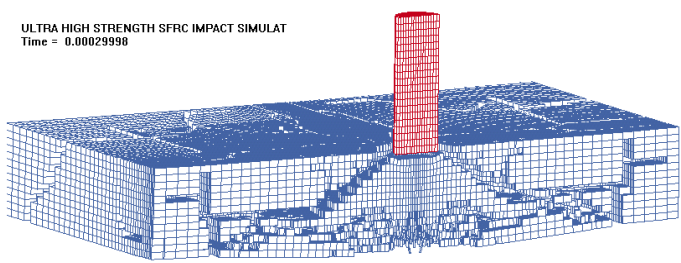

(b) Numerical analysis result

Figure 10: Comparison of the experimental damage and numerical results (RPC-F1-3). 


\section{References}

[1] Hanchak, S.J., Forrestal, M.J., Young, E.R. and Ehrgott, J.Q., Perforation of concrete slabs with $48 \mathrm{MPa}(7 \mathrm{ksi})$ and $140 \mathrm{MPa}(20 \mathrm{ksi})$ unconfined compressive strengths. International Journal of Impact Engineering 12, pp. 1-7. 1992.

[2] Dancygier, A.N., Yankelevsky, D.Z., High strength concrete response to hard projectile impact. International Journal of Impact Engineering 18, pp. 583-599, 1996.

[3] O'Neil, E.F., Neeley, B.D., Cargile, J.D., Tensile properties of very-highstrength concrete for penetration-resistant structures. Shock and Vibration 6, pp. 237-245, 1999.

[4] Luo, X., Sun, W., Chan, S.Y.N., Characteristics of high-performance steel fiber-reinforced concrete subject to high velocity impact. Cement and Concrete Research 30, pp. 907-914, 2000.

[5] Zhang, M.H., Shim, V.P.W., Lu, G., Chew, C.W., Resistance of highstrength concrete to projectile impact. International Journal of Impact Engineering 31, pp. 825-841, 2005.

[6] Richard P., Cheyrezy M., Composition of reactive powder concretes. Cement and Concrete Research 25, pp. 1501-1511, 1995.

[7] Chan, Y.W., Chu, S.H., Effect of silica fume on steel fiber bond characteristics in reactive powder concrete, Cement and concrete research 34, pp. 1167-1172, 2004.

[8] LSTC, LS-DYNA, Keyword User's Manual, Version 970, Livermore Software Technology Corporation, LSTC, Livermore. 2003.

[9] Malvar, L.J., Crawford, J.E., Weswvich, J.W., Simons, D., A plasticity concrete material model for dyna3d. International Journal of Impact Engineering 19, pp. 847-873. 1997.

[10] Ågårdh, L., Laine, L., 3D FE-simulation of high-velocity fragment perforation of reinforced concrete slabs. International Journal of Impact Engineering 22, 911-922, 1999.

[11] Holmquist, T.J., Johnson, G.R., and Cook, W.H., A computational constitutive model for concrete subjected to large strains, high strain rates, and high pressures. In: The 14th International Symposium on Ballistics, Qucbec City, Canada, pp. 591-600, 1993.

[12] Johnson, G.R., Computed radial stresses in a concrete target penetrated by a steel projectile. In: Proceedings of the 5th International Conference on Structures under shock and impact, Portsmouth, UK, pp. 793-806, 1998. 